\title{
Enhanced microwave shielding and mechanical properties of multiwall carbon nanotubes anchored carbon fiber felt reinforced epoxy multiscale composites
}

\author{
B. P. Singh • Preetam Bharadwaj • \\ Veena Choudhary $\cdot$ R. B. Mathur
}

Received: 14 February 2013/Accepted: 16 March 2013/Published online: 4 April 2013

(c) The Author(s) 2013. This article is published with open access at Springerlink.com

\begin{abstract}
Multi-walled carbon nanotubes (MWCNTs) were grown on carbon fiber (CF) felt by chemical vapor deposition that resulted into strongly anchored carbon nanotubes (CNTs) on the CF surface. These multiscale preforms were used as the reinforcement in epoxy resin to develop multi scale CF felt-MWCNT/epoxy composites. The flexural strength (FS) and the flexural modulus (FM) of the composites were found to increase with increasing amount of CNTs grown on CF felt surface. FS improved by $37 \%$, i.e. $119 \mathrm{MPa}$ compared to $87 \mathrm{MPa}$ for CF felt/epoxy composites prepared under identical conditions. The FM also improved by $153 \%$, i.e. $15.7 \mathrm{GPa}$ compared to 6.2 GPa for the CF/epoxy composites. The incorporation of MWCNTs on the CF felt produced a significant change in the electromagnetic interference shielding of these composites which improved from -21 to $-27 \mathrm{~dB}$ for CF feltMWCNT/epoxy multiscale composites in the $\mathrm{Ku}$ band $(12.4-18 \mathrm{GHz})$ and indicates the usefulness of these strong composites for microwave shielding.
\end{abstract}

Keywords Multiwalled carbon nanotubes - Microwave shielding · Carbon fiber felt · Multiscale composites

\footnotetext{
B. P. Singh $(\varangle) \cdot$ P. Bharadwaj · R. B. Mathur

Physics and Engineering of Carbon, Division of Materials

Physics and Engineering, CSIR-National Physical Laboratory,

New Delhi 12, India

e-mail: bps@mail.nplindia.org

R. B. Mathur

e-mail: rbmathur@mail.nplindia.org

B. P. Singh · V. Choudhary

Centre for Polymer Science and Engineering,

Indian Institute of Technology Delhi, Delhi 16, India
}

\section{Introduction}

Electromagnetic interference (EMI) is a complex and technical challenge these days which adversely affects and degrades the effective performance of a system. It is the undesired conducted or radiated electrical disturbance from an electrical or electronic apparatus which can interfere with the operation of other electrical or electronic apparatus. Today shielding against EMI is practiced by government, military, medical, private industries and R\&D laboratories. The importance of EMI shielding relates the high demand of speedy communication and reliability of electronic equipment, digital devices and wireless technology. Shielding is considered acceptable if it attenuates the intensity of electromagnetic field to an adequate level established by regulation of the electronic devices. It is also needed for deterring electromagnetic form of spying. It is therefore vital to develop new materials with enhanced EMI shielding capacity. It is well known that the shield should be conducting, therefore usually the shielding techniques focus on the use of standard metals and their composites which have shortcomings of limited mechanical flexibility, heavy weight, corrosion, physical rigidity and difficulty in tuning the shielding efficiency (Pande et al. 2009; Mathur et al. 2010; Qin et al. 2010). Further, metals mainly reflect the radiation and cannot be used in applications where absorption is the prime requisite.

Polymer composites containing carbon-based fillers [e.g. graphite, carbon black (CB), carbon fiber $(\mathrm{CF})$, carbon nanofiber (CNF) and carbon nanotubes (CNTs)] have been extensively investigated for use as EMI shields owing to their unique combination of electrical conduction, polymeric flexibility and light weight. The high conductivity, small diameter, high aspect ratio and superior mechanical properties of CNTs make them an excellent choice to 
create conductive composites for high performance EMI shielding materials (Pande et al. 2009; Mathur et al. 2008b).

Epoxy resins are well established as thermosetting matrices for advanced structural composites, displaying a series of promising characteristics for a wide range of applications owing to their excellent mechanical properties, low cost, ease of processing, good adhesion to many substrates, and good chemical resistance (Garg et al. 2011; Meenakshi and Sudhan 2011; Ruban et al. 2013). Several fibrous reinforcements, e.g. CF, glass fibers, aramid fiber (Kevlar fibers), etc. (Barrau et al. 2003; de Morais et al. 2003) have been used with epoxy resin as matrix in structurally strong composite materials for commercial applications such as in aerospace industry.

It is suggested that CNT reinforced epoxy composites can also be structurally strong EMI shielding materials. For a high value of EMI shielding, high loading of CNTs were used in the past. In one such study, Huang et al. (2007) have reported EMI-SE of $18 \mathrm{~dB}$ with $15 \mathrm{wt} \%$ small single walled carbon nanotubes (SWCNTs) and 23-28 dB with $15 \mathrm{wt} \%$ long SWCNTs in the frequency band of 8-12.4 GHz. Li et al. (2006) observed the SE of $49.2 \mathrm{~dB}$ at $10 \mathrm{MHz}$ with $15 \mathrm{wt} \%$ long CNTs. They reported that at higher frequencies, the composites exhibited shielding effectiveness of $20 \mathrm{~dB}$ at $1 \mathrm{GHz}$ for both 10 and $15 \mathrm{wt} \%$ SWCNT loadings. It is quite evident from the earlier reports that the reinforcement effect of $\mathrm{CNT}$ can be realized only for low loading level $(<1 \%)$ and afterward it starts to decrease dramatically due to several issues, e.g. dispersion, alignment and interface (Du et al. 2007; Lau and Hui 2002). It has been reported that beyond $0.6 \mathrm{wt} \%$ of MWCNTs, CNTs tend to agglomerate (Yang et al. 2009) resulting in poor bending strength and modulus of the composites.

Therefore, different routes have been adopted, notably a combination of CNTs and CF (Qian et al. 2010; Thostenson et al. 2009; Kim et al. 2007) that involves dispersion of CNTs into epoxy matrix followed by impregnation in carbon fabric. However, the above compositions had the limitation of reinforcing $<1 \%$ CNT beyond which the viscosity of the CNT-epoxy mix was raised so much that it became impossible to impregnate the fabric completely (Singh et al. 2012). In a recent review article, by Lubineau and Rahaman (2012), studies conducted on the role of nano reinforcements in mechanical properties were reviewed. It was concluded in the review that compressive strength was improved up to $39 \%$. According to them, there is a real potential for improving the compressive properties but the clear improvement in the flexural behavior was not realized. There is a further scope to study and clarify the issue. In our previous study, PAN-based CF fabric was used as a substrate to grow MWCNT and it was used as reinforcement in the epoxy resin (Singh et al. 2012; Mathur et al. 2012). Using the technique of CNT-grown CF fabric, $11.5 \mathrm{wt} \% \mathrm{CNT}$ of CF fabric was incorporated as one of the reinforcements in the epoxy composites. Beyond $11.5 \mathrm{wt} \%$ of CNTs, it was not possible to grow CNTs on the PANbased $\mathrm{CF}$ fabric. Here, we used three-dimensional porous $\mathrm{CF}$ felt and up to $18 \mathrm{wt} \%$ of MWCNT of CF felt was grown using chemical vapor deposition and these were used as reinforcements in epoxy resin. We also show that this multiscale composite can also serve as an efficient EMI shielding material with the combination of light weight, high strength and high electrical conductivity.

\section{Experimental}

\section{Growth of CNTs on CF felt}

CF felt (3D CF network) was chosen as a carbon substrate for the growth of CNTs. CNTs were grown on CF felt using the setup and the experimental conditions described earlier (Mathur et al. 2008a). Different amounts of CNTs were grown on the substrate by varying the deposition time. The substrate was removed after each experiment and weighed to determine the amount of CNT grown. The substrate was then sonicated in alcohol for $30 \mathrm{~min}$ to remove the loosely bonded CNTs on it. The weight uptake of the CNT grown on to the CF felt, selected for preparing composites, was calculated only after sonication. Different such batches were prepared with CNT uptake of 7.2, 8.4, 10, 11.6, 13.4, 14.7 and $17.9 \%$.

\section{Preparation of CF felt-CNT/epoxy multiscale composites}

The CNT-CF felt preforms were impregnated with epoxy matrix (Huntsman LY-556 resin and HY 5,200 hardener) to keep the reinforcement $(\mathrm{CF}+\mathrm{CNT})$ to the matrix ratio always as 40:60 by volume. The impregnated preforms were dried at room temperature to form the prepregs. These prepregs were stacked together to form a laminated assembly of the CNT-CF felt multiscale preforms. The laminates were then compression molded in a mold at $80{ }^{\circ} \mathrm{C}$ followed by a curing cycle, i.e. $2 \mathrm{~h}$ at $80^{\circ} \mathrm{C}$ followed by $4 \mathrm{~h}$ at $150{ }^{\circ} \mathrm{C}$ to obtain composite bars of size $60 \mathrm{~mm} \times 20 \mathrm{~mm} \times 2.5 \mathrm{~mm}$. The multiscale composite batches prepared with above different CNT uptake, i.e. 7.2, 8.4, 10, 11.6, 13.4, 14.7 and $17.9 \%$ were designated as FLCNT7, FLCNT8, FLCNT10, FLCNT12, FLCNT13, FLCNT15 and FLCNT18, respectively. In a separate experiment, laminates of as received $\mathrm{CF}$ felt were also compression molded under similar condition to prepare $\mathrm{CF}$ felt/epoxy composites designated as FLCNT0. Here we are 
able to grow CNTs up to 18 wt $\%$ because of high porosity in the felt and a large exposed surface area of the $\mathrm{CF}$ as compared to other CF networks as CF tows or CF fabric (Mathur et al. 2008a). For normal commercial CF-based composites for structural applications, the fiber volume content is generally kept between 50 and $60 \%$ by volume. It was not possible to use that high volume percent of the CF along with MWCNTs because of the large surface to volume ratio of the nanotubes. It was found that beyond 40 vol \% of CF in such cases the epoxy resin would not completely wet the reinforcement and the samples showed delamination under loading during flexural tests. The properties are compared on the basis of 40 vol\% CF feltbased epoxy composites.

\section{Characterization}

Scanning electron microscope (SEM, Leo S-440) was used to observe the morphologies of reinforcements (CNT and $\mathrm{CF}$ felt) and the fractured surface of the composites after mechanical testing to correlate the fracture behavior with the mechanical properties. The morphological details of CNTs were also observed under high-resolution transmission electron microscope (HR-TEM, Tecnai G20-stwin, $200 \mathrm{kV}$ ). A Raman spectrum of the CNTs was recorded using Renishaw Raman Spectrometer with green laser $(514 \mathrm{~nm})$ as an excitation source. The FS and FM were measured on Instron universal testing machine (model 4,411) under a three point flexural loading as per the ASTM standard D790. The span to depth ratio of the samples was kept as 20. At least five samples were tested for each batch and average is reported. The electrical conductivity of the composite samples was measured by four point contact method (Singh et al. 2008, 2011) using a Keithley 224 programmable current source for providing current. The voltage drop was measured by Keithley 197A auto ranging digital microvoltmeter. The values reported in text are averaged over five readings of voltage drops at different portions of the sample. The EMI shielding effectiveness measurements of the composites, i.e. FLCNT0, FLCNT8 and FLCNT18 were carried out on an Agilent E8362B vector network analyzer in the frequency range of $12.4-18 \mathrm{GHz}$ (Ku band).
Fig. 1 SEM image showing a uniform growth of CNTs (18 wt \%) over the surface of the $\mathrm{CF}$ felt preform, $\mathbf{b}, \mathbf{c}$ multiscale preform showing intrafilamentary growth of CNTs, d masking of $\mathrm{CF}$ monofilament with CNTs
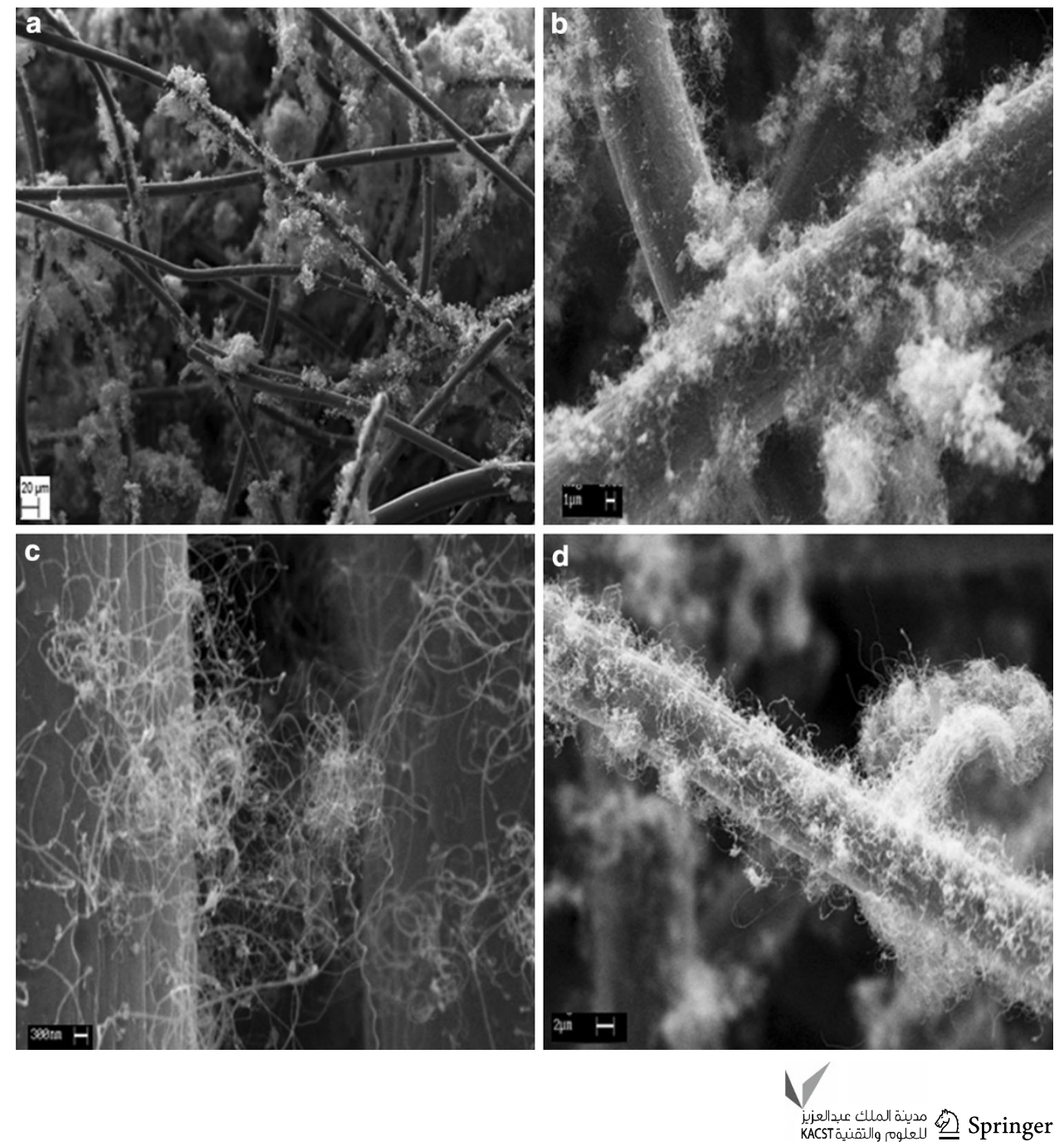

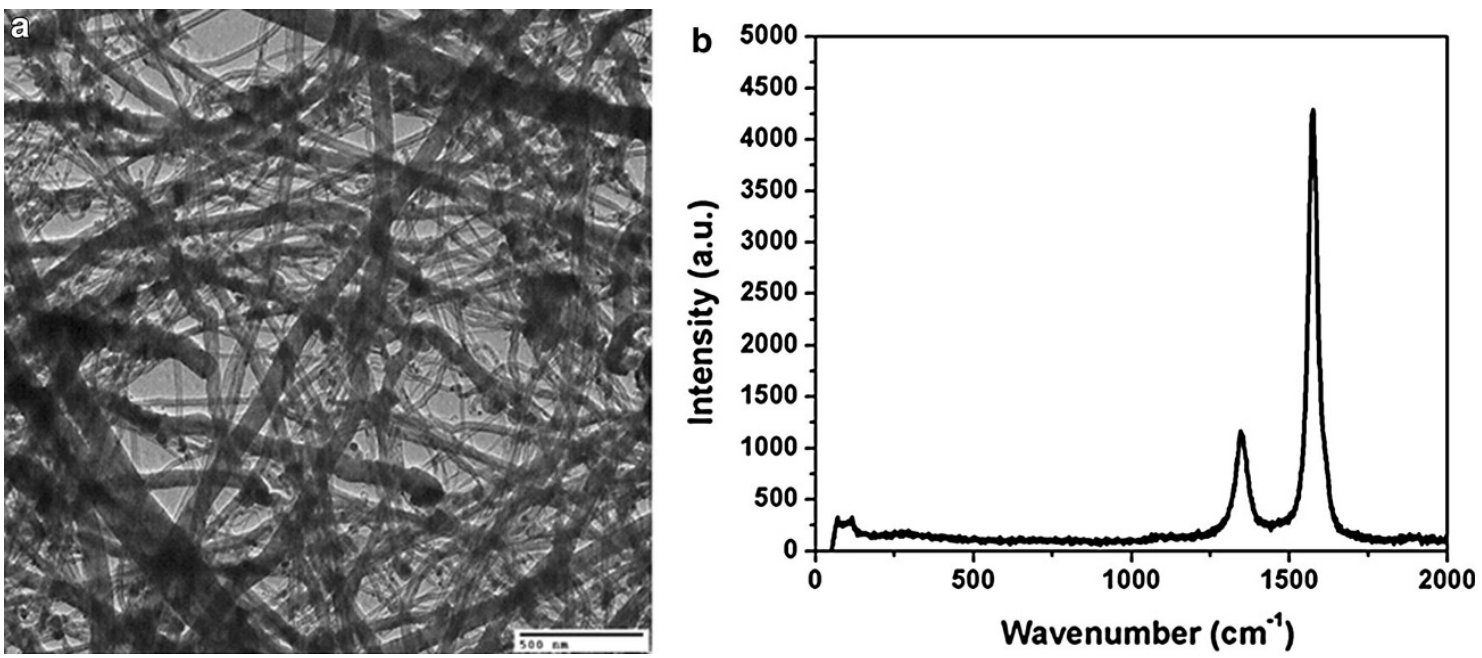

Fig. 2 a TEM and $\mathbf{b}$ Raman spectra of the scraped material from the CF felt

\section{Results and discussion}

Morphological features of the CF-CNT felt preforms

The SEM images of the multiscale preform show a uniform growth of CNTs throughout the surface of the felt (Fig. 1a). These tubes seem to be anchored strongly in the intrafilamentary spaces and the porosity between the cross-over spaces created by the CF as shown in Fig. $1 \mathrm{~b}$ and $\mathrm{c}$ and Fig. 1d shows a copious growth of CNTs on the carbon monofilament virtually covering its entire surface. The tubes are multiwalled in nature with metallic impurities as revealed by TEM (Fig. 2a). This is also confirmed by the Raman spectra of the scrapped material shown in Fig. $2 b$. We do not observe any peak in the region $150-300 \mathrm{~cm}^{-1}$ corresponding to radial breathing mode in single walled carbon nanotubes. The large value of the intensity ratio of the $G$ to $D$ band also suggests that these tubes are of reasonably good quality. The preform thus forms a nice combination of micro and nano reinforcement. The growth mechanism of CNTs on the surface of the CF felt has already been discussed in our previous study (Mathur et al. 2008a).

Mechanical properties of the composites

The results on the mechanical properties of the multiscale composites with different concentrations of MWCNTs grown on the CF felt are presented in Fig. 3a, b. The flexural strength (FS) is increased to $119 \mathrm{MPa}$ for the FLCNT18 as compared to only $87 \mathrm{MPa}$ for the FLCNT0. An overall improvement of $37 \%$ is therefore recorded for FLCNT18. The flexural modulus of the multiscale composites also shows gradual improvement with increasing concentration
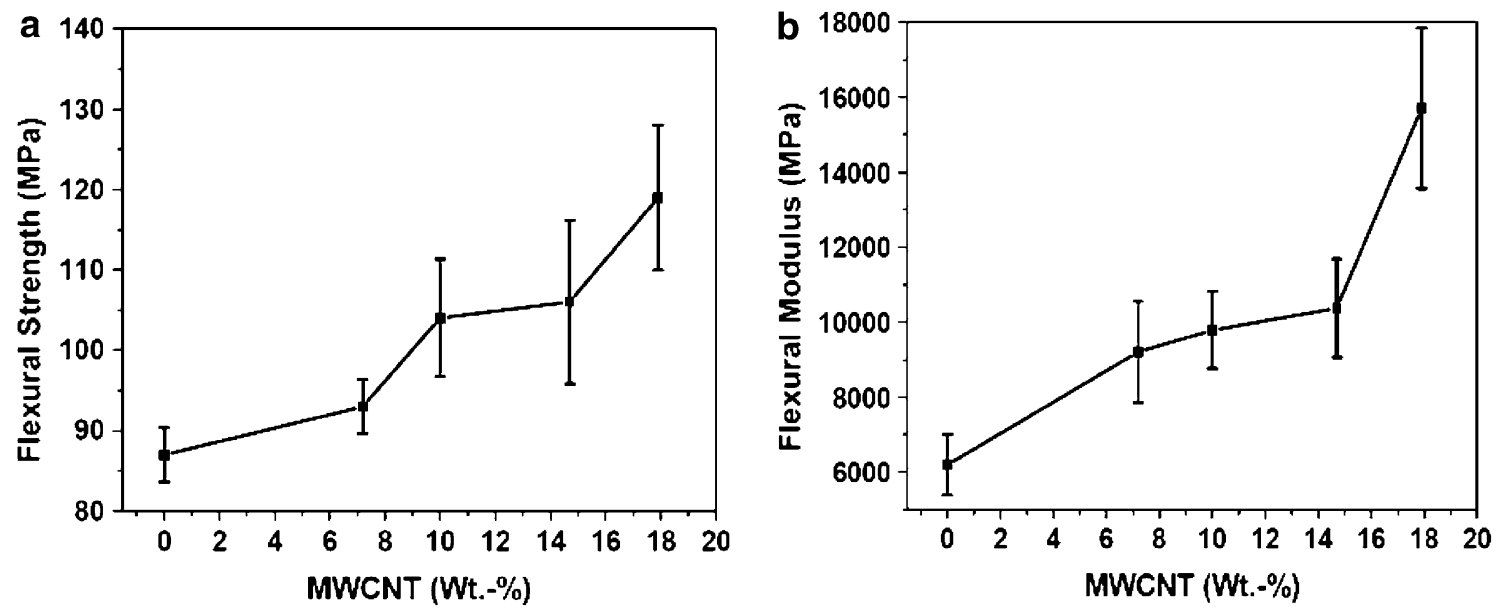

Fig. 3 a Variation in the FS of the CF felt-MWCNT/epoxy composites with increasing CNTs content in the multiscale preform. b Variation in the FM of the CF felt-MWCNTs/epoxy composites with increasing CNT content in the multiscale preform 

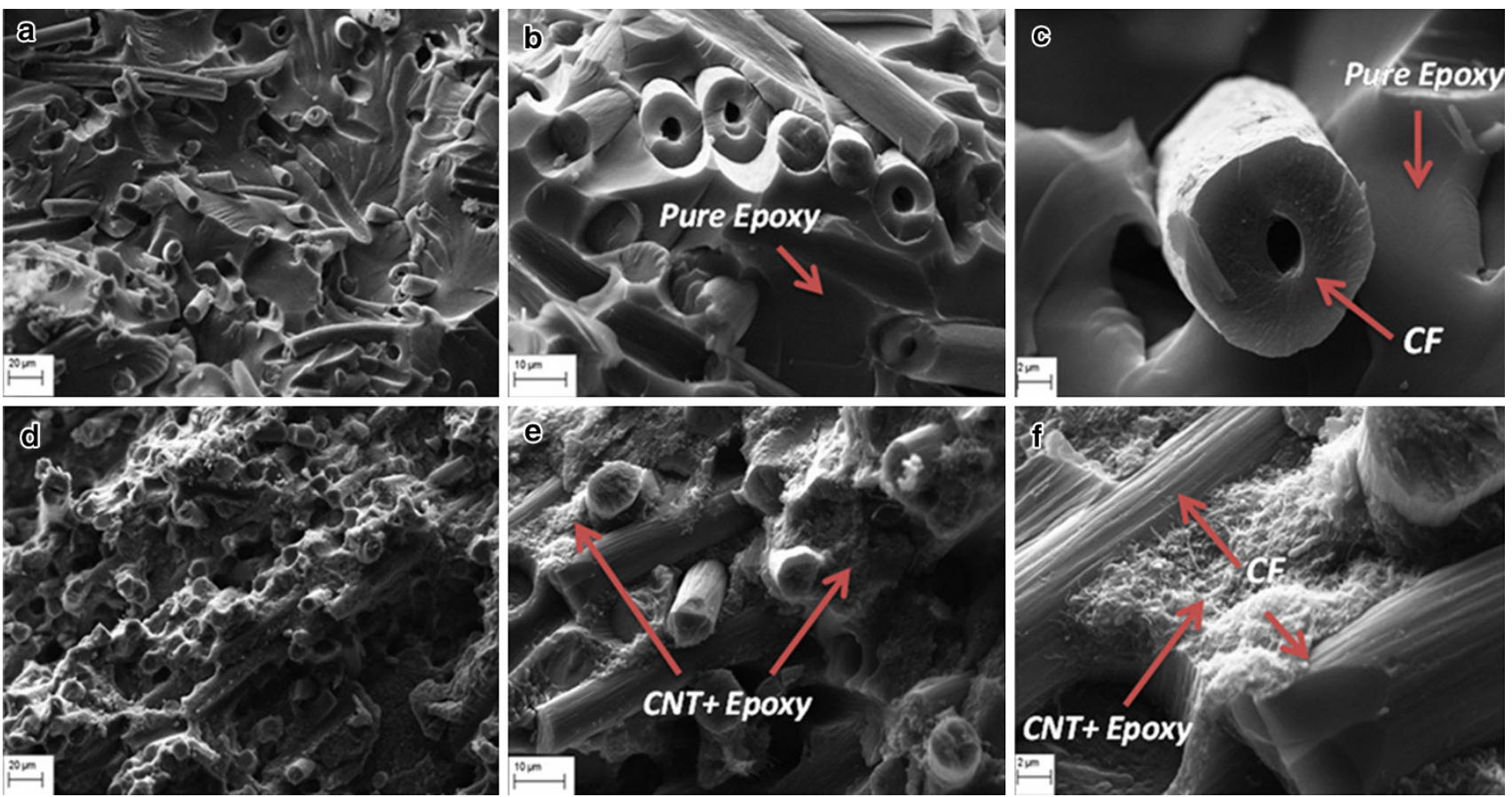

Fig. 4 SEM image of the a-c fracture surface of FLCNT0 at different magnifications, d-f fracture surface of FLCNT18 at different magnification

of MWCNTs (Fig. 3b). The flexural modulus (FM) of FLCNT18 shows a value of $15.7 \mathrm{GPa}$, an improvement of $\sim 153 \%$ over FLCNT0. These results show that by incorporation of the MWCNTs in the CF felt as reinforcement ( $\sim 18 \mathrm{wt} \%$ of $\mathrm{CF}$ felt), it is possible to achieve higher values of FS and FM compared to CF felt/epoxy composites.

The reason for the improvement in the mechanical properties of the multiscale composite can be understood by the SEM images of the cross section of their fractured surfaces. The fractured surface of the FLCNT0 (without CNT) is shown in Fig. 4a-c and the fractured surface of FLCNT18 is shown in Fig. 4d-f. It is observed that the MWCNTs are uniformly distributed in the entire volume of the epoxy matrix and interlocking between two CF. The CNTs-epoxy composite matrix seems to make strong bonds with the fiber showing less CF pull outs. The presence of MWCNTs would arrest the crack propagation in the matrix resulting into enhanced shear transfer stress for FLCNT18 as compared to FLCNT0. The fracture surface of FLCNT0 (Fig. 4a-c) shows brittle failure with fiber pull outs and uninhibited crack propagation through the matrix. The mechanical properties of FLCNT0 are comparatively lower therefore.

Electrical conductivity of the CF felt-MWCNTs/epoxy multiscale composites

Figure 5 shows the dependence of room temperature dc electrical conductivity $\left(\sigma_{\mathrm{dc}}\right)$ of the multiscale composites on the loading level of MWCNT. Pure epoxy is an electrical insulator with dc electrical conductivity value of $\sim 10^{-15} \mathrm{~S} \mathrm{~cm}^{-1}$ (Barrau et al. 2003). The observed rise in $\sigma_{\mathrm{dc}}$ with increased MWCNT content may be attributed to the increase in the number of conducting links within electrically insulting epoxy matrix. The added MWCNTs not only form the new links within epoxy matrix but also form conducting bridges between CF (shown in Fig. 4d-f). Such links are missing for FLCNT0 as shown in Fig. 3a-c. When the CNTs loading is increased to $18 \mathrm{wt} \%$, the electrical conductivity increased to $18.3 \mathrm{~S} \mathrm{~cm}^{-1}$ for FLCNT18 compared to $3.2 \mathrm{~S} \mathrm{~cm}^{-1}$ for FLCNT0. The achieved conductivity value was near the prescribed range for microwave shielding. Therefore, good microwave shielding response is expected.

\section{EMI shielding effectiveness measurement}

EMI shielding was measured on rectangular strips of composites inside the sample holder. The holder matches the internal dimensions of $\mathrm{Ku}$ band $(12.4-18 \mathrm{GHz})$ waveguide placed between the two ports of Vector Network Analyzer (VNA E8263BAgilent Technologies).

The EMI shielding is a direct result of reflection, absorption and multiple internal reflection losses at the existing interfaces, suffered by incident electromagnetic (EM) waves. EMI shielding effectiveness can be expressed as (Saini et al. 2009, 2011; Singh et al. 2013). 


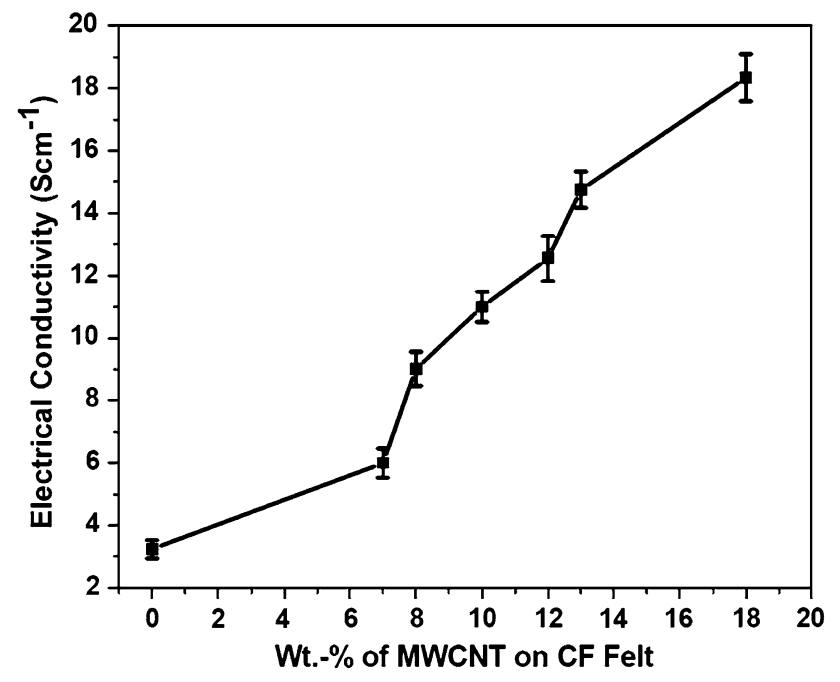

Fig. 5 Variation in the electrical conductivities of the $\mathrm{CF}$ feltMWCNT/epoxy composites with increasing MWCNTs contents in the preforms

$\mathrm{SE}_{\mathrm{T}}(\mathrm{dB})=10 \log \left[\frac{P_{\mathrm{T}}}{P_{\mathrm{I}}}\right]=20 \log \left[\frac{E_{\mathrm{T}}}{E_{\mathrm{I}}}\right]=20 \log \left[\frac{H_{\mathrm{T}}}{H_{\mathrm{I}}}\right]$

where $P_{\mathrm{I}}\left(E_{\mathrm{I}}\right.$ or $\left.H_{\mathrm{I}}\right)$ and $P_{\mathrm{T}}\left(E_{\mathrm{T}}\right.$ or $\left.H_{\mathrm{I}}\right)$ are the incident and transmitted electromagnetic powers (electric or magnetic field), respectively. The total shielding effectiveness can further be divided into three components:

$\mathrm{SE}_{\mathrm{T}}=\mathrm{SE}_{\mathrm{R}}+\mathrm{SE}_{\mathrm{A}}+\mathrm{SE}_{\mathrm{M}}$

where $\mathrm{SE}_{\mathrm{R}}, \mathrm{SE}_{\mathrm{A}}$ and $\mathrm{SE}_{\mathrm{M}}$ are shielding effectiveness due to reflection, absorption and multiple reflections, respectively. The scattering parameters $S_{11}$ (or $S_{22}$ ) and $S_{21}\left(\right.$ or $S_{12}$ ) of a two port network analyzer can be related with reflectance and transmittance as:

$\mathrm{T}=\left|\frac{E_{\mathrm{T}}}{E_{\mathrm{I}}}\right|^{2}=\left|S_{21}\right|^{2}=\left|S_{12}\right|^{2}$

and

$R=\left|\frac{E_{\mathrm{R}}}{E_{\mathrm{I}}}\right|^{2}=\left|S_{11}\right|^{2}=\left|S_{22}\right|^{2}$

The absorbance $(A)$ can be written as:

$A=(1-R-T)$

Here, it should be noted that the absorption coefficient is given with respect to the power of the incident EM wave. When $\mathrm{SE}_{\mathrm{A}}$ is $\geq 10 \mathrm{~dB}, \mathrm{SE}_{\mathrm{M}}$ is negligible (Saini et al. 2009). Therefore, third term in Eq. 2 (i.e. $\mathrm{SE}_{\mathrm{M}}$ ) vanishes and $\mathrm{SE}_{\mathrm{T}}$ can be conveniently expressed as:

$\mathrm{SE}_{\mathrm{T}}=\mathrm{SE}_{\mathrm{R}}+\mathrm{SE}_{\mathrm{A}}$;

Further, the relative intensity of the effectively incident EM wave inside the materials after first reflection is based on the quantity $(1-R)$. The effective absorbance $\left(A_{\text {eff }}\right)$ can be described as $A_{\text {eff }}=(1-R-\mathrm{T}) /(1-R)$ after normalization with respect to the power of the effectively incident EM wave inside the shielding material. Therefore, it is convenient to express the reflection and effective absorption losses in the form of $-10 \log (1-R)$ and $-10 \log$ $\left(1-A_{\mathrm{eff}}\right)$, respectively, i.e.

$\mathrm{SE}_{\mathrm{R}}=10 \log (1-R)$

$\mathrm{SE}_{\mathrm{A}}=10 \log \left(1-A_{\text {eff }}\right)=10 \log \frac{T}{1-R}$

The term skin depth $(\delta)$ is the depth of penetration at which the intensity of the electromagnetic wave is reduced to 1/e of its original strength (Kumar et al. 2013). The $\delta$ is dependent upon various parameters like angular frequency $(\omega)$, real relative permeability $\left(\mu^{\prime}\right)$ and total conductivity $\left(\sigma_{\mathrm{T}}=\sigma_{\mathrm{dc}}+\sigma_{\mathrm{ac}}\right)$, i.e. $\delta=\sqrt{2 / \omega \mu \sigma_{\mathrm{T}}}$.

Further, the angular frequency $(\omega)$ dependence of reflection and absorption losses can be expressed in the terms of total conductivity $\left(\sigma_{\mathrm{T}}\right)$, real permeability $\left(\mu^{\prime}\right)$, skin depth $(\delta)$ and thickness $(t)$ of the shield material as (Colaneri and Shacklette 1992).

$$
\begin{aligned}
\mathrm{SE}_{\mathrm{R}}(\mathrm{dB}) & =-10 \log _{10}\left(\frac{\sigma_{\mathrm{T}}}{16 \omega \varepsilon_{o} \mu^{\prime}}\right) \\
\mathrm{SE}_{\mathrm{A}}(\mathrm{dB}) & =-20 \frac{t}{\delta} \log _{10} e=-8.68\left(\frac{t}{\delta}\right) \\
& =-8.68 t\left(\frac{\sigma_{\mathrm{T}} \omega \mu^{\prime}}{2}\right)^{\frac{1}{2}}
\end{aligned}
$$

Variation of $\mathrm{SE}_{\mathrm{T}}$ with frequency of samples designated as FLCNT0, FLCNT8 and FLCNT18 is shown in Fig. 6. The $\mathrm{SE}_{\mathrm{T}}$ value improved from $-21 \mathrm{~dB}$ (FLCNT0) to $-27 \mathrm{~dB}$ (FLCNT18). When we further investigated the reflection and absorption components of these composites as a function of CNTs content at a particular frequency in the $\mathrm{Ku}$ band region, it was found that as the MWCNTs content increases, both $\mathrm{SE}_{\mathrm{R}}$ and $\mathrm{SE}_{\mathrm{A}}$ increases as shown in Fig. 7. Therefore, the addition of MWCNT resulted in the enhancement of $\mathrm{SE}_{\mathrm{T}}$, i.e. from -21 to $-27 \mathrm{~dB}$. The primary mechanism of EMI shielding is usually a reflection of the electromagnetic radiation incident on the shield, which is a consequence of the interaction of EMI radiation with the free electrons on the surface of the shield. As a result, the shield has to be highly electrically conducting. Therefore, increase in the electrical conductivity from 3.2 to $18.3 \mathrm{~S} \mathrm{~cm}^{-1}$ resulted in the enhancement in the $\mathrm{SE}_{\mathrm{R}}$. Absorption is usually a secondary mechanism of EMI shielding where electric dipoles in the shield interact with the electromagnetic fields in the radiation. The increasing difference between $\mathrm{SE}_{\mathrm{R}}$ and $\mathrm{SE}_{\mathrm{A}}$ with increase in CNT loading may therefore be due to interfacial polarization of epoxy by CNT which increases the absorption component. 


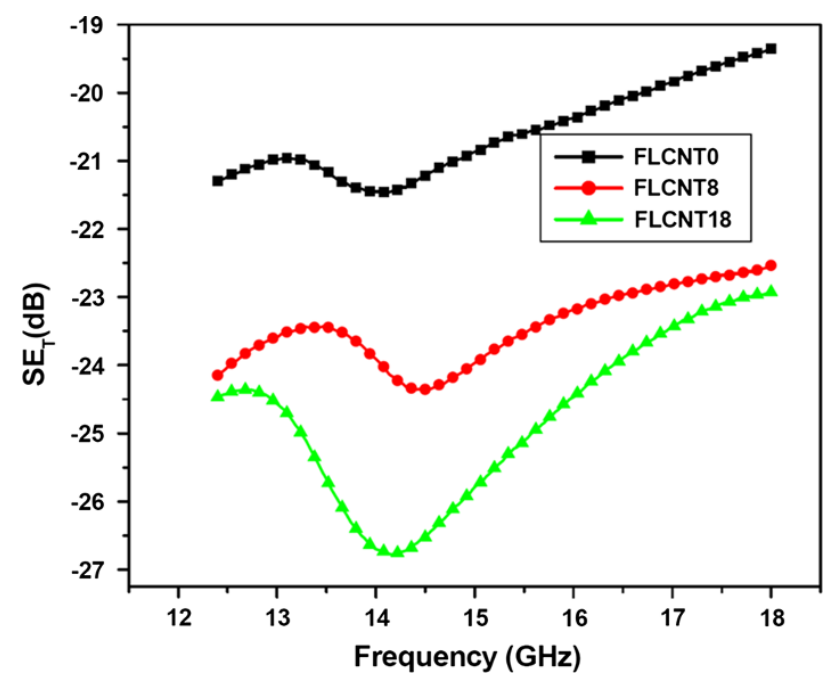

Fig. 6 Variation of total EMI shielding effectiveness with frequency and growth of MWCNTs on CF felt

The low skin depths and high conductivity $\left(\sigma_{\mathrm{T}}\right)$ values in the microwave region often result in contribution of $\mathrm{SE}_{\mathrm{A}}$ becoming much more compared to $\mathrm{SE}_{\mathrm{R}}$. Therefore, absorption acts as dominant shielding mechanism with nominal reflection values. The enhanced absorption can be explained in terms of reduction in skin depth with the increase in both permeability (due to presence of iron as shown in Fig. 2a) and electrical conductivity (due to available highly electrical conducting MWCNTs) (Singh et al. 2012). Equation 9 predicts that reduction in skin depths can improve the contribution of absorption loss in the EMI shielding. In other words, at same thickness, the material with lowest skin depth is expected to give the maximum absorption loss. The variation of frequencydependent skin depth of different materials, i.e. FLCNT0, FLCNT8 and FLCNT18 is shown in Fig. 8. It reveals that as the amount of growth of MWCNTs increases, the skin depth decreases from FLCNT0 to FLCNT18. Therefore, enhanced $\mathrm{SE}_{\mathrm{A}}$ value improved the $\mathrm{SE}_{\mathrm{T}}$ value of the composites.

\section{Conclusions}

A process has been developed to grow MWCNTs on CF felt as substrate. This multiscale substrate proved to be an effective reinforcement for producing high strength low weight strong composites with improved mechanical properties compared to those established by CF felt/epoxy composites $(0 \% \mathrm{CNT})$. The addition of CNTs showed considerable improvement in the FS (37\%) and FM $(153 \%)$ of the resulting multiscale composite relative to the CF felt/epoxy composites. In addition, with the incorporation of MWCNTs in the CF felt, EMI shielding

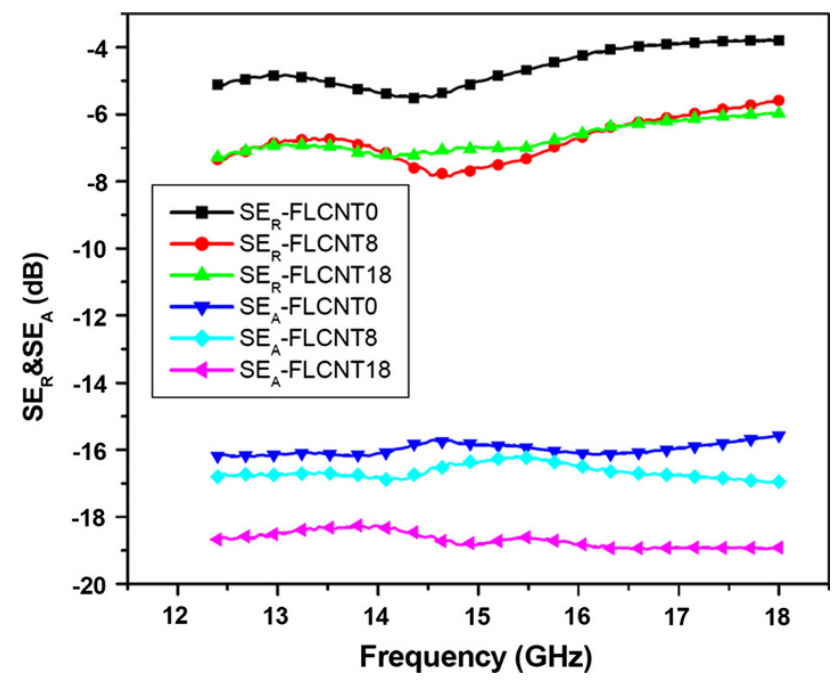

Fig. 7 Variation of reflection and absorption loss with frequency and growth of MWCNTs on CF felt

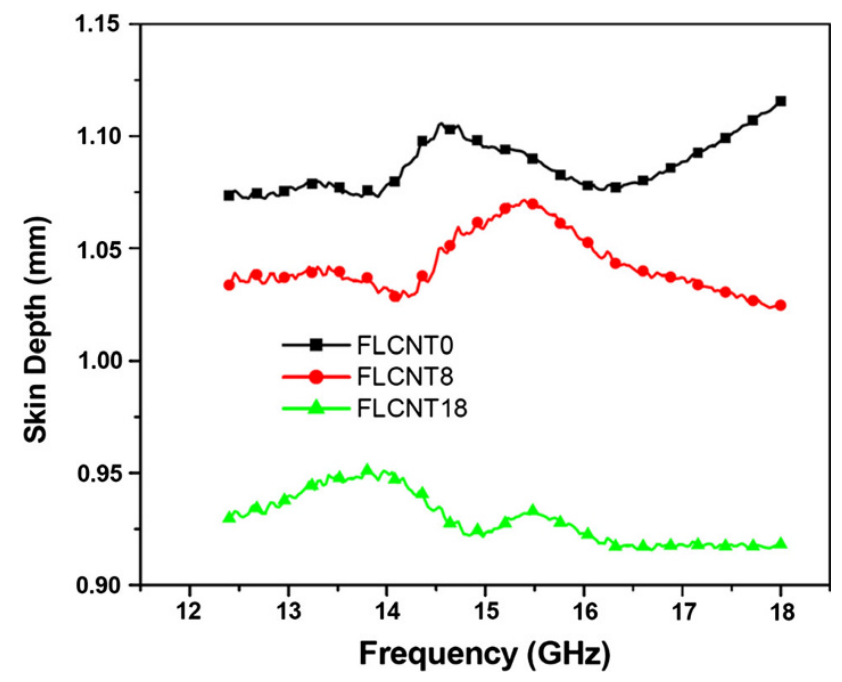

Fig. 8 Variation in skin depth with frequency and the growth of MWCNTs on CF felt

effectiveness was also found to be enhanced from -21 (FLCNT) to $-27 \mathrm{~dB}$ (FLCNT18). The high value of shielding effectiveness demonstrates the potential of these materials as microwave shielding materials in $\mathrm{Ku}$ band (12.4-18 GHz).

Acknowledgments Authors are highly grateful to the Director, NPL, for his kind permission to publish the results. Authors would like to thank the conducting polymer section, NPL New Delhi for helping in the EMI shielding measurements. Mr. K.N. Sood and Mr. Jay Tawale are also thanked for their support in carrying out SEM.

Open Access This article is distributed under the terms of the Creative Commons Attribution License which permits any use, distribution, and reproduction in any medium, provided the original author(s) and the source are credited. 


\section{References}

Barrau S, Demont P, Perez E, Peigney A, Laurent C, Lacabanne C (2003) Effect of palmitic acid on the electrical conductivity of carbon nanotubes-epoxy resin composites. Macromolecules 36:9678-9680

Colaneri NF, Shacklette LW (1992) EMI shielding measurements of conductive polymer blends. IEEE Trans Instrum Meas 41:291-297

de Morais WA, d'Almeida JRM, Godfroid LB (2003) Effect of the fiber reinforcement on the low energy impact behaviour of fabric reinforced resin matrix composite materials. J Braz Soc Mech Sci Eng 25:325-328

Du JH, Bai J, Cheng HM (2007) The present status and key problems of carbon nanotube based polymer composites. EXPRESS Polym Lett 1:253-273

Garg P, Singh BP, Kumar G, Gupta T, Pandey I, Seth RK, Tandon RP, Mathur RB (2011) Effect of dispersion conditions on the mechanical properties of multi-walled carbon nanotubes based epoxy resin composites. J Polym Res 18:1397-1407

Huang Y, Li N, Ma Y, Feng D, Li F, He X, Lin X, Gao H, Chen Y (2007) The influence of single-walled carbon nanotube structure on the electromagnetic interference shielding efficiency of its epoxy composites. Carbon 45:1614-1621

Kim YA, Kamio S, Tajiri T, Hayashi T, Song SM, Endo M, Terrones M, Dresselhaus MS (2007) Enhanced thermal conductivity of carbon fiber/phenolic resin composites by the introduction of carbon nanotubes. Appl Phys Lett 90:093125

Kumar R, Dhakate SR, Gupta T, Saini P, Singh BP, Mathur RB (2013) Effective improvement of the properties of light weight carbon foam by decoration with multi-wall carbon nanotubes. J Mater Chem A. doi: 10.1039/C3TA10604G

Lau KT, Hui D (2002) The revolutionary creation of new advanced materials-carbon nanotube composites. Compos Part B-Eng 33:263-277

Li N, Huang Y, Du F, He XB, Lin X, Gao HJ, Ma YF, Li FF, Chen YS, Eklund PC (2006) Electromagnetic interference (EMI) shielding of single-walled carbon nanotube epoxy composites. Nano Lett 6:1141-1145

Lubineau G, Rahaman A (2012) A review of strategies for improving the degradation properties of laminated continuous-fiber/epoxy composites with carbon-based nanoreinforcements. Carbon 50:2377-2395

Mathur RB, Chatterjee S, Singh BP (2008a) Growth of carbon nanotubes on carbon fibre substrates to produce hybrid/phenolic composites with improved mechanical properties. Compos Sci Technol 68:1608-1615

Mathur RB, Pande S, Singh BP, Dhami TL (2008b) Electrical and mechanical properties of multi-walled carbon nanotubes reinforced PMMA and PS composites. Polym Compos 29:717-727

Mathur RB, Pande S, Singh BP (2010) Properties of PMMA/carbon nanotubes nanocomposites. In: Polymer nanotube nanocomposites: Synthesis properties, and applications. vol 11, pp 177
Mathur RB, Singh BP, Tiwari PK, Gupta TK, Choudhary V (2012) Enhancement in the thermomechanical properties of carbon fibre-carbon nanotubes-epoxy hybrid composites. Int $\mathbf{J}$ Nanotechnol 9:1040-1049

Meenakshi KS, Sudhan EPJ (2011) Development and study of the thermal and electrical behavior of TGDDS epoxy nanocomposites for high-performance applications. Appl Nanosci 1:109-115

Pande S, Singh BP, Mathur RB, Dhami TL, Saini P, Dhawan SK (2009) Improved electromagnetic interference shielding properties of MWCNT-PMMA composites using layered structures. Nanoscale Res Lett 4:327-334

Qian H, Greenhalgh ES, Shaffer MSP, Bismarck A (2010) Carbon nanotube-based hierarchical composites: a review. J Mater Chem 20:4751-4762

Qin FX, Peng HX, Pankratov N, Phan MH, Panina LV, Ipatov M, Zhukova V, Zhukov A, Gonzalez J (2010) Exceptional electromagnetic interference shielding properties of ferromagnetic microwires enabled polymer composites. J App Phys 108: 044510

Ruban YJ, Mon SG, Roy DV (2013) Mechanical and thermal studies of unsaturated polyester-toughened epoxy composites filled with amine-functionalized nanosilica. Appl Nanosci 3:7-12

Saini P, Choudhary V, Singh BP, Mathur RB, Dhawan SK (2009) Polyaniline-MWCNT nanocomposites for microwave absorption and EMI shielding. Mater Chem Phys 113:919-926

Saini P, Choudhary V, Singh BP, Mathur RB, Dhawan SK (2011) Enhanced microwave absorption behavior of polyaniline-CNT/ polystyrene blend in $12.4-18.0 \mathrm{GHz}$ range. Synth Met 161:1522-1526

Singh BP, Singh D, Mathur RB, Dhami TL (2008) Influence of surface modified MWCNTs on the mechanical, electrical and thermal properties of polyimide nanocomposites. Nanoscale Res Lett 3:444-453

Singh BP, Prabha SP, Gupta T, Garg P, Kumar G, Pande I, Pande S, Seth RK, Dhawan SK, Mathur RB (2011) Designing of multiwalled carbon nanotubes reinforced low density polyethylene nanocomposites for suppression of electromagnetic radiation. J Nanopart Res 13:7065-7074

Singh BP, Choudhary V, Saini P, Mathur RB (2012) Designing of epoxy composites reinforced with carbon nanotubes grown carbon fiber fabric for improved electromagnetic interference shielding. AIP Adv 2:022151

Singh BP, Prasanta, Choudhary V, Saini P, Pande S, Singh VN (2013) Enhanced microwave shielding and mechanical properties of high loading MWCNT-epoxy composites. J Nanopart Res 15:1-12

Thostenson ET, Gangloff JJ, Li C, Byun JH (2009) Electrical anisotropy in multiscale nanotube/fiber hybrid composites. Appl Phys Lett 95:073111

Yang K, Gu MY, Guo YP, Pan XF, Mu GH (2009) Effects of carbon nanotube functionalization on the mechanical and thermal properties of epoxy composites. Carbon 47:1723-1737 